\title{
The Flipped Classroom: A New Attempt in English Interpreting Teaching in Universities
}

\author{
Yingfei Xiong \\ School of Foreign Languages, Hubei University of Science and \\ Technology, Xianning City, Hubei Province, 437000, China
}

\begin{abstract}
Under the background of information network, the flipped classroom provides a new way for the construction of English interpreting teaching model. At present, there exist many problems in interpreting teaching in regular higher education institutions. Therefore, it is necessary to carry out interpreting teaching reform by virtue of the teaching philosophy of the flipped classroom. Based on the author's learning and teaching experience, this paper firstly analyzed the flipped classroom and its significance for interpreting teaching. Then, the author put forward the design and implementation of the flipped classroom in interpreting teaching. Finally the article summarized the problems and suggestions in implementing the flipped classroom in English interpreting teaching.

Keywords: English; Interpreting teaching; Flipped classroom; Design; Implementation
\end{abstract}

\section{Introduction}

The flipped classroom is a bran-new teaching model, which change people's way of thinking by changing the teaching process. Students can complete their own learning in the flipped classroom by virtue of videos and other information technology with no limit on time and space. Researches have found that students' mastery of the knowledge that they learn independently is better than that they learn in the traditional teaching classroom[1]. The flipped classroom is not to reverse the order of class learning and learning after class simply. The scale and influence of the flipped classroom in basic subjects of college English is not great, 
so it is necessary to carry out such practice in interpreting teaching. The interaction between students or teachers and students benefits the applied subject teaching .

\section{The Flipped Classroom and Its Significance for Interpreting Teaching}

\subsection{The cognition of the essence of the flipped classroom}

Most of scholars at home and abroad define the flipped classroom from the perspective of the essence of learning and practice process. The essence of learning emphasizes that human beings acquire experience and knowledge, and master objective laws in the process of cognition and practice; human obtain relatively everlasting adaptive psychological changes through practice or training. Practice process generally refers to that students determine the theme and content of practice through discussions, assign tasks to the members and ask relevant professional teachers for specialized theoretical knowledge guidance. After that, students conduct corresponding practical operation on the subject content to find problems and search for an answer from their teachers, so as to complete the practice[2]. The principle of the flipped classroom accords with the essence of learning and the practice process. Learners obtain the relevant knowledge and experience, and master the law in the course by watching teaching videos independently. Students learn the content before class by themselves and they can seek professional guidance on difficulties in knowledge from teachers in class. After that, students can make further corresponding exercises to digest and consolidate the knowledge that they have learned. The teacher has changed the role from the speaker who teach knowledge in original classroom to the question answerer, practice director, exercise designer and partner.

\subsection{The significance of the flipped classroom for interpreting teaching}

With the advent of the digital age, the development of education technology, the maturity of social networks, and the sharing of education resources, teachers can use some teaching models and methods that can not be utilized before. The implementation process of the flipped classroom helps teachers who teach interpreting solve many problems. For example, teaching hours are insufficient; theory and skill learning is the main part in class; the teaching lacks classroom practice; the interpreting teaching method and environment are simple. The flipped classroom takes students as the real subject in the interpreting class. Changes in the teaching form stimulate students' interest in learning, so as to give full play to their subjective initiative. The flipped classroom in the interpreting class can help teachers build simulation interpreting practice for learners, create an atmosphere for interpreting and help students improve their psychological quality and adaptability of the interpreting. Besides, teachers can give timely and direct on-the-spot instruction to make the practice more effective. Classroom 
teaching content is no longer boring theoretical study, but interpreting activity related to the market and social needs. The application of a multiple evaluation mechanism with student self-evaluation, mutual evaluation and teacher evaluation in the interpreting classroom helps students experience the professional characteristics of the interpreter, which is beneficial to improve the quality of interpreting teaching and train high-quality professional interpreters[3].

\section{The Design and Implementation of the Flipped Classroom in Interpreting Teaching}

\subsection{The design of the flipped classroom in interpreting teaching}

In the interpreting teaching, the author draws lessons from the interpreting training model proposed by teachers who have taught interpreting for many years and takes the model as teaching guiding principle. Interpreting training model emphasizes the dynamic interaction between interpreting skills and linguistic knowledge, and between extra-linguistic knowledge, discourse analysis and intercultural communication strategies. This model proposes the important principle that interpreting training should take skill training as the main task. Based on the interpreting training model and problems in interpreting teaching, the author tries to solve the practical problems in interpreting teaching by virtue of the flipped classroom under the background of the network platform. The classroom has realized the following reversals: interpreting teaching has changed the teaching model from one-way passive teaching model with interpreting skills and linguistic knowledge as the main part to a two-way active interpretation skill learning model with students' self-learning and knowledge internalization as the main part; interpreting teaching should change the traditional teaching classroom where the teacher is the core in the class to give lectures and make demonstrations and student just make practice[4]. Then, the teaching should construct a student-centered teaching model. In this model, students can learn micro-course before class and they can make personal presentation or interpreting practice in class. After that, teachers may help them solve problems, give them guidance and monitor the class. After class, students can make simulation training; the single summative interpreting assessment model should be ended and colleges should construct a diverse valuation mechanism with student selfassessment, mutual evaluation and teacher evaluation.

\subsection{The implementation of the flipped classroom in interpreting teaching}

(1) The construction of the training model with the flipped classroom as the concept where students can learn knowledge independently and internalize training skills.

Interpreting skill training should follow students' learning laws and carry out specialized interpretation training step by step. Besides, it should achieve the integration cultivation of bilingual interpretation skills, short-term and long-term 
memory ability, interpretation note-taking strategy, cross-cultural awareness, public speaking ability, good psychological quality and excellent professionalism. The author takes the cultivation of students' short-term memory ability as an example. Teachers can record micro-videos and upload them to the website of boutique courses before class. The teaching content of the videos includes shadowing practice, repetition, summarize, summary and other related skill practice in interpreting[5]. The teacher allows students to sum up their self-study content and give feedback and corrections. Then teachers can strengthen the training content to enhance students' short-term memory ability. After class, teachers should continue to provide relevant interpretation materials and upload them to the website, so that students can expand the practice and record their training content in audios or videos. When they upload their learning results to the website, teachers can grade their learning and give them feedback.

(2) The construction of a diversified teaching model with the Internet as the platform

Different from online teaching or distance education, the flipped classroom is not a teaching method that just relies on the network, and it is a diversified teaching model that integrates classroom teaching and network platform with the use of network platforms. This model can distribute the content of the theoretical skill and practice in interpreting reasonably with the combination of learning in and after class. The cyclic and sustaining teaching process greatly increased the opportunities and time for students to learn.

(3) The construction of a diversified evaluation mechanism in interpreting ability assessment

The teaching place in the flipped classroom is not limited to the classroom and it extends to the network and even social activities. Therefore, the single summative assessment cannot assess students' interpretation ability objectively. Interpreting teaching should adopt diversified and comprehensive assessment methods to evaluate students' pre-class learning results, personal presentation in class and the homework after school. Teachers can monitor students' pre-class learning and assign homework through the network. They can check and evaluate students' pre-class learning effect according to their frequency of submitting homework, quality of the work and classroom performance. The evaluation of presentations in class is not determined by teachers[6]. In the flipped classroom, students' selfevaluation and mutual evaluation is important to evaluate presentations in class. For the completion of the task, teachers can give a comprehensive evaluation on team cooperation, communication and the conformity to the market demand. At the same time, teachers should encourage students to take interpretation qualification certificate examinations and encourage them to participate in various interpretation contests actively to enhance their sense of competition in interpretation learning[7]. 


\section{Problems and Suggestions}

First of all, the flipped classroom emphasizes that students use their intrinsic motivation and their subjective initiative in learning in order to carry out preschool and after-school learning effectively. For students with poor learning ability and bad habits, teachers can not stimulate their internal motivation within a short time and it is more difficult to stimulate their motivation in interpretation. If there is no reasonable means of monitoring and evaluation, students' selflearning power is still insufficient or they just select some interpreting tasks. Second, because of the lack of direct communication with students when recording videos before class, teachers can not keep abreast of students' learning problems to give timely feedback. If teachers completely rely on the website to teach extensive content in interpreting after class, they can not control the completion effectiveness. Due to the lack of direct guidance, students' interpreting work quality lacks stability. Third, the network monitoring is a more difficult evaluation part. Teachers lacks comprehensive network technology to assist their assessment in monitoring students' learning results. In procedural evaluation, assessments include teacher evaluation, student assessment and student self-assessment, which is likely to result in the lack of preciseness in the assessment results and instability of students' performance. Finally, most of the interpreting teaching depends on Chinese teachers, which is a shortcoming in the interpreting classroom. The flipped classroom can add videos recorded by foreign teachers or IMOOC content related to interpreting in foreign countries to make the interpreting teaching diverse and real.

\section{Conclusion}

In general, the significance of the flipped classroom in interpreting is to make students become the subject of learning and make them understand the need for lifelong learning. Science and technology are advancing. The rational use of the network and computer technology makes flipped classroom become an effective model in English interpreting teaching, but it is only a tool to optimize teaching. To improve the quality of teaching with this tool, teachers need to improve their quality and design the interpreting class elaborately to guide students. The flipped classroom is a supplement to the traditional teaching and it aims to enable students to internalize knowledge in limited time. However, it takes a long time for academic circles to test and evaluate whether the flipped classroom adapts to the actual situation of college English interpreting teaching in China.

\section{Acknowledgements}

The research work was supported by the research project in Hubei University of Science and Technology: The Difficulty Discrimination of Interpreting Teaching 
Materials - A case Study based on the Interpreting Course in Our College, number ky14013.

\section{References}

[1] Qin Hui. An Overview and Reflection on the Interpreting Teaching Based on the Flipped Classroom. The Guide of Science and Education, (11), pp.50-51, 2014.

[2] Jiang Hong. An Empirical Study on Undergraduate Interpreting Teaching Based on the Flipped Classroom. English Square, (10), pp.129-131, 2016.

[3] Wang Jianna. A Practice Research of English Interpreting Teaching Based on the Flipped Classroom. Journal of Ningbo University (Educational Science Edition), (05), pp.114-118, 2016.

[4] Xu Yucheng. An Exploration of the Teaching Model of Vocational Business Interpretation Based on the Flipped Classroom. English Teachers, (12), pp.25-29 2016.

[5] Yao Wenjuan. An Action Research of the Construction of Interpreting Teaching Model in the Flipped Classroom. Journal of Jiamusi Vocational Institute, (06), 356-357, 2016.

[6] Chen Shengbai. An Innovative Research of the Interpreting Teaching Model in the Flipped Classroom Based on Corpus. Computer-assisted Foreign Language Education, (06), pp.31-36, 2015.

[7] Wang Honglin. An Action Research of the Interpreting Teaching Based on the Flipped Classroom. Chinese Translators Journal, (01), pp.59-62, 2015. 